\title{
Teacher Practice on Online Formative Assessment
}

\author{
Siti Nurfiqah*, Fazri Nur Yusuf \\ English Education Program, Universitas Pendidikan Indonesia, Bandung \\ *Corresponding author. Email: sitinurfiqah17@upi.edu
}

\begin{abstract}
This paper aims to investigate (1) the struggles teacher encounters in his/her school's online formative assessments, and (2) the strategies teacher employs to deal with struggles in his/her school's online formative assessments. This research applied a qualitative study approach. A three year-experienced teacher who teaches 210 students in online teaching and learning has involved as the participant in this study. The data were gained from the interview to an EFL teacher of a school in Bandung. Result showed that the teacher has a strong interpretation of the formative assessment and the preparation of assessment is necessary in order to determine the academic success of students during the course. However, the study found the teacher was not ready to face the transition from face-to-face learning to online learning; the teacher could not optimize the implementation of the formative assessment and the students had been passive in online learning so that the achievement of the students could not clearly demonstrate the success of the students. It is also found that not every student received the benefit from on-going activities and certain strategies used by the teacher. It can be assumed that online teaching and learning practice is a new way of practicing for some teachers. Without the planning and experimentation of online teaching assessment activities, the teachers do not know precisely how the activity is carried out. This lack of experiments therefore leaves the responsibility of deciding whether the strategy is appropriate for students.
\end{abstract}

Keywords: Online formative assessment, formative assessment, teacher's practice

\section{INTRODUCTION}

In the field of English Foreign Language (EFL), teaching activities and assessments assessment are interwoven that one cannot have a comprehensive picture if either of them is missed from considerations. Assessment is the core of formal higher education (Gikandi, Davis, \& Morrow, 2011) and a very important aspect of the teaching process (Álvarez, Lafuente, \& Remesal, 2014; Brink \& Lautenbach, 2011). The implementation of assessment gives the information for both teachers and students about teaching and learning succeed since assessment can determine the skills and knowledge of students and also ensure that they achieve the desired learning outcomes (Stödberg, 2012). In fact, creating an assessment is a costly and long process that produces tension and requires time and a considerable effort for instructors and learners involved in it (Hettiarachchi, Huertas, \& Mor, 2013). Therefore, the need to implement information technology has emerged in order to solve this situation and in the light of recent developments in higher education, leading to an increasing importance of e-learning and technical learning, which offer new opportunities for teaching assessment (Stödberg, 2012). However, systemically implementing formative assessment approaches across schools and districts can be a challenge in that they are not based on a product, technology or system that can be installed or implemented. Changing the relationship between teachers and students and managing the multitude of these interactions and relationships is at the core of effective formative assessment processes and, thus, requires the understanding and strategies of how formative assessments perform in a virtual learning environment.

Formative assessment is considered as a continuous activity or process which forms part of educational activities which are related explicitly to existing teaching and learning activities in the classroom. Formative assessment is carried out to determine student understanding, learning needs and learning progress in a given unit (Karimi, 2014). Formative assessment help teachers define areas of difficulty for students which can be used to inform or adapt instruction (Gong, Marion, Perie, \& Wurtzel, 2007) in order to comprehend educational materials and acquire basic skills to reach learning competence (Furtak \& Ruiz-Primo, 2007). For further, formative assessment allows teachers to make adjustments and revisions on learning materials based on 
feedback about student performance (Popham, 2006) as well as a set of tools to monitor student progress during learning (Dunn \& Mulvenon, 2009; Stiggins, 2002) to be more effective in teaching.

English teachers nowadays are expected to have a clear understanding of the formative assessment which influence their ability to identify follow-up actions that need to do to enhance their students' academic success and develop their professional teaching practices. Teachers' knowledge of the formative assessment includes their understanding of the importance of the formative assessment, the characteristics and principles of the formative assessment, the ability to provide feedback, and the ability to carry out follow-up activities. Popham (2008) adds a crucial clarification: formative assessment is always a scheduled process; it does not happen unexpectedly. Other concepts expand the idea of formative assessment as a process by integrating assessment tools where they can be incorporated seamlessly into instructional practices (Heritage, 2007). for the express purpose of collecting feedback to guide teaching or learning. Herman, Osmundson, and Silver (2010) state that good quality of formative assessment is vital to improve the students' learning outcomes. Furthermore, as an attempt to help students built a growth brain, teachers should actively assist students in finding out which learning strategies are better tailored to them since Johnson, Johnson, and Roseth's (2006) study shows that student success improves as teachers can make students involved in learning. Thus, technology seems to play an important role in developing strategies in the learning process and to enhance the quality of assessment.

The sophisticated technology can generate a virtual learning environment that allows people to connect and communicate (Isaías, Miranda, \& Pífano, 2014). As Kalz, Ras, and Whitelock (2016) stated that in order to promote the effectiveness of formative assessment practices, technology can play a dual role in the process: it can serve as a facilitator to provide self-assessment and feedback, and new assessment practices can be developed.

Gikandi et al., (2011) view that technology should promote responsive teaching and assessment to accommodate various learning abilities and styles. The use of multimedia as the product of ICT can help to learn and to teach activities by providing the opportunities for learner to be more creative and increase the students' confidence by its non-judgmental correction of errors, allowing for having experimentation in a supportive environment (Dugard \& Hewer, 2003). However, the complete realization of formative assessments involves careful design, monitoring, strategies, and feedback communication to students in a clear and meaningful timeframe (Davis, Derrick, Ponton, \& Rovai, 2006; Isaias, Issa, \& Issa 2014) in order to improve their overall experience of education (Dibbs, Glassmeyer, \& Jensen, 2011).

A series of studies of online formative assessment have been contextualised to concerns about the effectiveness and quality of online courses. For example, a work conducted by Bahati, Fors, Hansen, Nouri, and Mukama (2019) showed that technology was used to allow and promote creative formative assessment practice in real classroom settings. New types of learning activities and the technology-enabled instructional activities have been developed and tested to transform formative assessment practices to advance student learning. Another work by Hodgson and Pang (2012) showed that there is a growing awareness among educators of the importance of redesigning assessment practices so that students can benefit from the process of assessment. The undergraduate students on their work showed evidence that through weekly formative assessment exercises, they had experienced an improved learning experience. Most students demonstrated good interest in the tasks, and some reported that they made great efforts to carry out them. They also become aware of the gaps in their results and have more learning opportunities which support them to have more time for self-regulated learning and reflection on what was learned. Moreover, a review of literature by Gikandi et al., (2010) have identified that online formative assessment may provide a structured approach to promote meaningful interactions and the development of a collaborative online learning community and in turn, to improve opportunities through continuous monitoring and provision of formative feedback for effective learner support and scaffolding learning. Meanwhile Daly, Pachlera, Morb, and Mellarb (2010) provided evidence that online formative assessment involved both teachers and learners in meaningful educational interactions. They also add that online formative assessment provides opportunities for enhanced interactivity and formative feedback.

Most of the several studies above agree that technology give positive contribution to the implementation of formative assessment in virtual context. However, the recognition that learners may not progress while interacting with technical and social services must be part of the challenge of formative assessment. As human actors, it is the learners and teachers that eventually decide the formative effects of technology interaction, but technologies can influence the potential for this to happen. It is only when there is a greater understanding of successful learning that it is possible to recognize and maximize the ability of electronic potential to contribute to formative assessment. Moreover, the practice will involve concerns such as the ability and credibility of creating formative assessments in an online environment and understanding how formative assessments work in virtual learning environment. Equally significant is how formative 
assessment in virtual setting can support the learning and teaching of students within the teaching strategy where the problem of implementing online distance learning such as the internet connection area, digital literacy and economic problem on the society are still found. Therefore, the two focuses: (1) the struggles teacher encounters in his/her school's online formative assessments, and (2) the strategies teacher employs to deal with struggles in his/her school's online formative assessments.

\section{METHOD}

Through qualitative analysis research design, this study seeks to reveal the struggle teacher encounters in his/her school's online formative assessments, and the strategies teacher employs to deal with his/her struggles in school's online formative assessments.

This research was conducted in a senior high school EFL teacher in one district in Bandung. Site was selected by considering the teachers' availability to be observed and the time allocation provided to teach English.

An EFL teacher in senior high schools in one district in Bandung is involved in this study because the teacher implements formative assessment in online classroom activities. The participant is a male teacher who has been graduated from Education University in Indonesia. He has teaching experience for three years and still count. During the online learning, the English subject is scheduled for three times in a week with 60 minutes in a teaching hour. Moreover, due to the virtual situation, the teacher teaches a big number of students: 210 students.

A zoom interview with a teacher participated in this present study was conducted to understand current practices and arguments for and against online formative assessment. This study is used a case study approach. The findings of the study were reported descriptively.

The tool of data collection is interview. The data is collected by providing questions related to teachers' knowledge of formative assessment implementation, such as how formative assessment perceived by the teacher, and the strategies teachers formulate to get obtain the desire learning outcome. This interview section seemed like a discussion in and the interview was leading by the researcher by asking the list of questions for the participants. The teacher was free to share and explore their points of view based on the questions delivered. During the interview section, the researcher used Zoom recorder to ensure the information from the participant was recorded well.

In data analysis, the researcher described the findings descriptively. In the process of interview analysis, the interview has done through zoom interview and will be recorded. The researcher listened the Zoom recorded interview for several times. After that, the researcher carried out as soon as possible the transcription after the actual interview. Then, the researcher identified substantive statements by stop-go analysis and write down when one statement comes up; and ask someone to double-check by doing the same kind of what have researcher done. After finishing this part, the researcher re-listened to the recorder with complete transcription and categorize and highlight the essential point. After that, the researcher checked the researcher's judgment and make summarize.

\section{FINDINGS AND DISCUSSION}

The paragraphs below explore the findings and discussion of the present study and answers the focus in this study, which are: (1) the struggles teacher encounters in his/her school's online formative assessments, and (2) the strategies teacher employs to deal with struggles in his/her school's online formative assessments.

\subsection{Teacher's Perception of Online Formative Assessment}

The teacher stated that the formative assessment is a continuous process that helps the teacher know the success of the students and the degree at which the student can achieve the content. The teacher performs this assessment at the end of learning material of every unit to ensure that students understand the materials rather than getting the grade of the student. The teacher further argued that the implementation of the formative assessment provides him the knowledge about the level of performance of the students in relation to the topic or content they have mastered. The teacher frequently uses a formative assessment to identify students' understanding about the lesson given.

However, the current situation of the Covid-19 pandemic has shifted the learning system from face-toface learning to online learning. In a virtual situation, the teacher argued that he usually viewed the formative assessment as a summative assessment. He uses the formative assessment to achieve the grade of the student, not the progress.

From the teacher's statement related to teacher's perception on formative assessment, it is clear that the teacher has a proper understanding of formative assessment. The teacher interview revealed that he had a good and positive understanding of the formative assessment. On the other hand, the teacher cannot optimize the implementation of the formative assessment virtually. In this way, the formative assessment has the summative purposes. In fact, summative assessment can also serve as a formative function if the data gathered are used to guide learning in subsequent units of the course. 


\subsection{The strategies teacher used in implementing online formative assessment}

When doing face-to-face teaching practice, the teacher argued that he was attempting to clarify the topic to be related to each other: from one topic to another particular subject. For example, he offers students a copy of the statement and its interpretation as an illustration of the current content they are studying. It is intended to remind students of the previous material the teacher had taught. According to him, this kind of strategy helps him as a teacher to make sure that students understand the previous subject, and also to make students more conscious of the current subject they are grappling with.

However, when the researcher asked the teacher about the strategies of face-to-face instruction during the implementation of the formative assessment. In the online learning environment, the formative assessment is also seen as an attempt to monitor the success of students and, of course, in a virtual context. In this situation, the teacher found that he could not optimize the implementation of the formative assessment, and the result is far from what he has achieved when the teacher and the students learn face-to-face. He said that the students had been passive in online learning, even he has encouraged the students, for example giving questions about the material he has given. Faced with this case, the teacher focuses on carrying out a formative assessment in a virtual task. He then realized that the findings of the students could not clearly demonstrate the success of the students. According to him, not all students necessarily complete the exercise by themselves. Often the teacher found that there was the same result between students in their answer sheets. Not only did he have a copy of the result, but the teacher has found that the answer is very good with the sophisticated use of words, and thus, according to his prediction, most students use the google machine to answer the question since the result does not represent the standard of English skills of the students.

In addition, at the conclusion of the interview, the instructor admits that he was not ready to face the transition from face-to-face learning to online learning. He added that he had no images of how to implement a formative assessment strategy during online learning. So open-ended questions, the teacher's comment, are most likely to be included in classroom assessments.

Related to the strategy implementation teacher used in implementing online formative assessment, it showed that the teacher uses teaching strategies to know how intensely students understand or integrate the subject and to assess whether or not their responses meet the learning objectives. However, the strategies he has for face-toface activities cannot be well applied during virtual practices. It can be argued that not all face-to-face formative assessment strategies are working with online learning. It can also be argued by his comment on the change in practice: from face-to-face to virtual, a teacher also wants more training time to formulate and adapt new strategies from researchers around the world.

\section{CONCLUSION}

Generally speaking, the data analysis revealed that the participants in the study - the teacher, in general, viewed a strong interpretation of the formative assessment. Teachers agree that the preparation assessment is a very necessary part of the teachinglearning process in order to determine the academic success of students during the course. However, our study has shown that not every student receives on-going activities and certain strategies used by the teacher. If the strategies are not effective, the desired learning results would not be reached.

Pedagogical theory remains the same, but practice differs. Teachers need to reconsider online pedagogy in order to build successful teaching assessment strategies that include evocative deep learning and assessment. It is also necessary for teachers to consider distinct assessment beliefs and not assume, for example, that the belief in what is to be evaluated would be compatible with the belief in the strategy used to assess. Teachers need to be updated with proper training as the training assessment skills are constantly developed.

It can also be assumed that online teaching and learning practice is a new way of practicing for some teachers. Without the planning and experimentation of online teaching assessment activities, the teachers do not know precisely how the activity is carried out. This lack of experiments therefore leaves the responsibility of deciding whether the strategy is appropriate for students. This may leave the teacher open to claims of bias or unethical practice which may also result in ineffective formative assessment for both teachers and students.

\section{REFERENCES}

Bahati, B., Fors, U., Hansen, P., Nouri, J., \& Mukama, E. (2019). Measuring learner satisfaction with formative e-assessment strategies. International Journal of Emerging Technologies in Learning (iJET), 14(07), 61-79.

Brink, R., \& Lautenbach, G. (2011). Electronic assessment in higher education. Educational Studies, 37(5), 503-512.

Daly, C., Pachler, N., Mor, Y., \& Mellar, H. (2010). Exploring formative e-assessment: Using case stories and design patterns. Assessment \& Evaluation in Higher Education, 35(5), 619-636.

Dugard, C., \& Hewer, S. (2003). Impact on learning: What ICT can bring to MFL in KS3. London: CILT. 
Dunn, K. E., \& Mulvenon, S. W. (2009). A Critical Review of research on formative assessments: The limited scientific evidence of the impact of formative assessments in education. Practical Assessment, Research, and Evaluation, 14(1), 7.

Gikandi, J. W., Morrow, D., \& Davis, N. E. (2011). Online formative assessment in higher education: A review of the literature. Computers \& education, 57(4), 2333-2351.

Glassmeyer, D. M., Dibbs, R. A., \& Jensen, R. T. (2011). Determining utility of formative assessment through virtual community: Perspectives of online graduate students. Quarterly Review of Distance Education, 12(1), 23.

Heritage, M. (2007). Formative assessment: What do teachers need to know and do? Phi Delta Kappan, 89(2), 140-145.

Herman, J. L., Osmundson, E., \& Silver, D. (2010). Capturing quality in formative assessment practice: Measurement challenges. CRESST Report, 770.

Hettiarachchi, E., Huertas, M. A., \& Mor, E. (2013). Skill and knowledge e-assessment: A review of the state of the art. IN3 Working Paper Series.

Hodgson, P., \& Pang, M. Y. (2012). Effective formative e-assessment of student learning: A study on a statistics course. Assessment \& Evaluation in Higher Education, 37(2), 215-225.

Isaías, P., Miranda, P., \& Pífano, S. (2014). Higher education and web 2.0: Theory and practice. In P. Jean-Eric. (Ed.), higher education (pp. 88-106). IGI Global.

Issa, T., Isaias, P., \& Issa, T. (2014). Does 'MP3' Audio Feedback Enhance Students' Learning Skills?: An international case study. The International Journal of Learning, 19, 15-28.

Johnson, D. W., Johnson, R. T., \& Roseth, C. (2006). Do peer relationships affect achievement. The cooperative link, 21(1), 2-4.

Karimi, M. N. (2014). Iranian EFL Teachers' Perceptions of Dynamic Assessment: Exploring the role of education and length of service. Australian Journal of Teacher Education, 39 (8), 143-162.

Lafuente, M., Remesal, A., \& Álvarez Valdivia, I. M. (2014). Assisting Learning in E-Assessment: A closer look at educational supports. Assessment \& Evaluation in Higher Education, 39(4), 443-460.

Perie, M., Marion, S., Gong, B., \& Wurtzel, J. (2007). The Role of Interim Assessments in a Comprehensive Assessment System: A Policy Brief. Aspen Institute.
Popham, W. J. (2006). Assessment for educational leaders. Pearson/Allyn and Bacon.

Popham, W. J. (2008). Formative assessment: Seven stepping-stones to success. Principal Leadership, 9(1), 16-20.

Ras, E., Whitelock, D., \& Kalz, M. (2016). The promise and potential of e-assessment for learning. In P. Reimann, S. Bull, M. D. Kickmeier-Rust, R. Vatrapu, \& B. Wasson (Eds.), Measuring and visualising learning in the information-rich classroom (pp. 21-40). London: Routledge.

Rovai, A. P., Ponton, M. K., Derrick, M. G., \& Davis, J. M. (2006). Student evaluation of teaching in the virtual and traditional classrooms: A comparative analysis. The Internet and Higher Education, 9(1), 23-35.

Ruiz-Primo, M. A., \& Furtak, E. M. (2007). Exploring teachers' informal formative assessment practices and students' understanding in the context of scientific inquiry. Journal of Research in Science Teaching, 44(1), 57-84.

Stiggins, R. J. (2002). Assessment crisis: The absence of assessment for learning. Phi Delta Kappan, 83(10), 758-765

Stödberg, U. (2012). A research review of eassessment. Assessment \& Evaluation in Higher Education, 37(5), 591-604. 